thrombectomy may be excluded for these critically ill patients, although an emergency transplant remains an option.

\section{CONCLUSIONS}

Coronary occlusion as a result of aortic thrombosis is a rare but catastrophic complication of venoarterial ECMO as a bridge to delayed surgery for post-MI VSR. During this highly thrombogenic period, LV pulsatility and aortic valve opening must be strictly preserved and heparin therapy closely monitored. A heart transplant should be considered in the most severe cases when the risk of surgical repair is considered too high.

\section{References}

1. Tang GHL, Malekan R, Kai M, Lansman SL, Spielvogel D. Peripheral venoarteria extracorporeal membrane oxygenation improves survival in myocardial infarction with cardiogenic shock. J Thorac Cardiovasc Surg. 2013;145:e32-3.

2. Abedi-Valugerdi G, Gabrielsen A, Fux T, Hillebrant CG, Lund LH, Corbascio M Management of left ventricular rupture after myocardial infarction solely with ECMO. Circ Heart Fail. 2012;5:e65-7.

3. Muehrcke DD, McCarthy PM, Stewart RW, Seshagiri S, Ogella DA, Foster RC et al. Complications of extracorporeal life support systems using heparin-bound surfaces: the risk of intracardiac clot formation. J Thorac Cardiovasc Surg. 1995; 110:843-51.

4. Doll N, Kiaii B, Borger M, Bucerius J, Krämer K, Schmitt DV, et al. Five-year results of 219 consecutive patients treated with extracorporeal membrane oxygenation for refractory postoperative cardiogenic shock. Ann Thorac Surg. 2004;77: 151-7; discussion 157

\title{
Mitral valve repair using autologous leaflet tissue as neochordae
}

\author{
Peter Benedikt, MD, MSc, ${ }^{a}$ Christian Punzengruber, MD, ${ }^{\mathrm{b}}$ Laszlo Milassin, MD, ${ }^{\mathrm{a}}$ and \\ Choi Keung Ng, MD, ${ }^{c}$ Wels and Innsbruck, Austria
}

Since the introduction of standardized mitral valve repair, techniques have continuously evolved. Different methods are known to avoid or minimize tissue resection, like artificial chordal replacement or autologous pericardial leaflet augmentation. ${ }^{2}$ We report the case of a patient who underwent mitral valve repair 20 years ago using autologous tissue leaflet as neochordae according to a technique of Gregory and colleagues. ${ }^{3}$

From the Department of Cardio, Thoracic, and Vascular Surgery, ${ }^{\mathrm{a}}$ General Hospital Wels, Wels, Austria; Division of Cardiology, ${ }^{\mathrm{b}}$ Department of Internal Medicine, General Hospital Wels, Wels, Austria; and Private Practice, ${ }^{\mathrm{c}}$ Innsbruck, Austria.

Disclosures: Authors have nothing to disclose with regard to commercial support.

Received for publication July 30, 2014; accepted for publication Aug 29, 2014; available ahead of print Sept 22, 2014.

Address for reprints: Peter Benedikt, MD, MSc, Department of Cardio, Thoracic, and Vascular Surgery, General Hospital Wels, Grieskirchnerstrasse 42, 4600 Wels,

Austria (E-mail: peter.benedikt@klinikum-wegr.at).

J Thorac Cardiovasc Surg 2014;148:e217-8

$0022-5223 / \$ 36.00$

Copyright (C) 2014 by The American Association for Thoracic Surgery

http://dx.doi.org/10.1016/j.jtcvs.2014.08.047

\section{CLINICAL SUMMARY}

A 52-year-old man was admitted to our hospital for severe regurgitation with prolapse and chordal rupture at the posterior leaflet of a myxomatous mitral valve. Coronary angiography results and left ventricular function were normal.

\section{SURGICAL TECHNIQUE}

After median sternotomy cardiopulmonary bypass was set up by bicaval cannulation. Heart arrest was achieved with cold crystalloid cardioplegia. The mitral valve was exposed via right atriotomy through the interatrial septum.

After mitral valve analysis, which depicted a flail leaflet in $\mathrm{P} 2$ and accompanying prolapse in $\mathrm{P} 1$ and $\mathrm{P} 3$, the valve was repaired by using a strip of autologous tissue of the posterior mitral leaflet as neochordae.

Two parallel incisions at a distance of $4 \mathrm{~mm}$ were set in the prolapsing segment of the posterior mitral leaflet
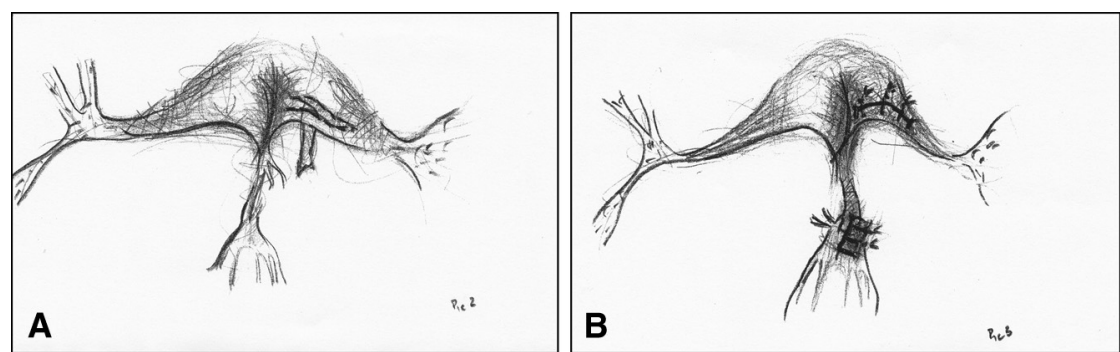

FIGURE 1. A, Two parallel incisions at a distance of $4 \mathrm{~mm}$ are set in the prolapsing segment of the posterior mitral leaflet beginning $2 \mathrm{~mm}$ from the annulus and ending $3 \mathrm{~mm}$ before the free edge. B. The excised strip is anchored to the papillary muscle with pericardial pledgeted-supported 5-0 polypropylene sutures. 


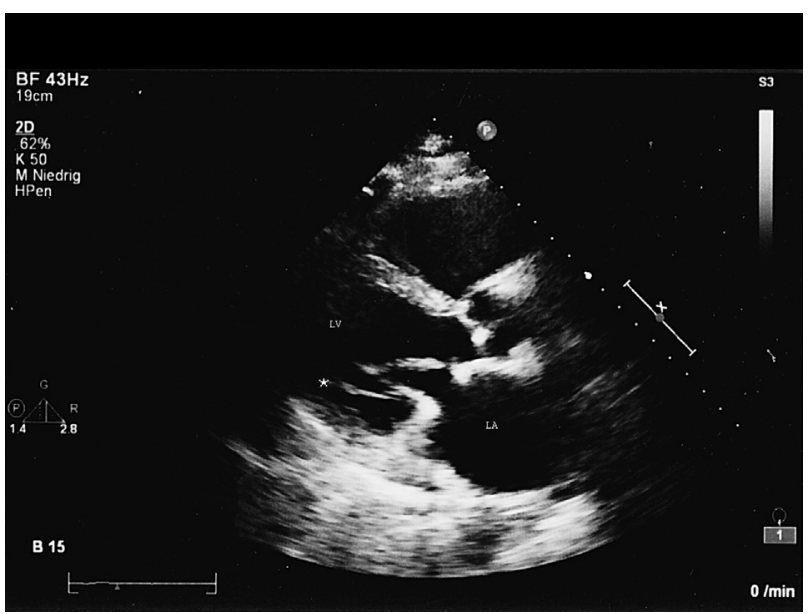

FIGURE 2. Transthoracic echocardiography performed 20 years after surgery. $L V$, Left ventricle; $L A$, left atrium. *Autologous chordae.

beginning $2 \mathrm{~mm}$ from the annulus and ending $3 \mathrm{~mm}$ before the free edge (Figure 1, A). This excised strip was anchored to the papillary muscle with pericardial pledgetedsupported 5-0 polypropylene sutures (Figure 1,B). The incision in $\mathrm{P} 2$ was closed with continuous 5-0 polypropylene sutures. Annuloplasty was performed with a rigid prosthetic ring (Carpentier $32 \mathrm{~mm}$, Edwards Lifesciences, Irvine, Calif). After weaning from cardiopulmonary bypass intraoperative transesophageal echocardiography revealed a fully competent mitral valve.

The postoperative course was uneventful and the patient was discharged 10 days after surgery.

In the meantime the patient was repeatedly admitted to the hospital because of hypertension and atrial flutter that was first seen 2 years after surgery, a pacemaker implantation to correct bradycardia and atrial fibrillation 10 years ago, and cicumflex stenting because of single vessel disease 6 years ago.

The 20-year echocardiography follow-up confirmed an effective mitral valve repair functioning with the strip of autologous tissue as neochordae (Figure 2). Regurgitation was trivial and left ventricular function was slightly globally reduced as a result of left atrial dilatation.

\section{DISCUSSION}

With the introduction of standardized surgical techniques mitral valve repair has become reproducible and prevalent. Leaflet resection followed by either annulus plication or sliding leaflet plasty has been the gold standard to repair posterior leaflet disorder and has demonstrated excellent long-term results. Leaflet prolapse with limited residual tissue is best addressed with conservative resection or chordal reconstruction. ${ }^{4}$

Instead of midsize to large leaflet tissue resection, chordal reconstruction avoids the sacrifice of leaflet tissue for the sake of a larger coaptation surface. Furthermore, by preserving posterior leaflet tissue, the anatomic and dynamic relationship is maintained, allowing the physiologic distribution of forces and stresses on valve components and the left ventricle. ${ }^{5}$ These facts apply to autologous reconstruction, which has the advantage of avoiding additional extraneous material.

Gregory and colleagues ${ }^{3}$ described a technique using autologous valve tissue as neochordae to reconstruct a disorder of the anterior leaflet. We report the case of a patient with a characteristic pathology of the posterior leaflet that was repaired using this technique 20 years ago. A current echocardiograph conducted on this patient demonstrates that the application is fully competent, even after 20 years.

In our experience, 3 patients with different anterior and posterior leaflet pathologies have undergone operation successfully with the technique introduced by Gregory and colleagues $^{3}$ and achieved good short- and midterm results.

Autologous reconstruction is applicable for long-term durability and is not cost-prohibitive. Autologous chordal replacement provides an accurate alternative technique, broadening the surgical armamentarium in mitral valve repair.

\section{References}

1. Carpentier A. Reconstructive valvuloplasty. A new technique of mitral valvuloplasty [article in French]. Presse Med. 1969;77:251-3.

2. Ng CK, Nesser J, Punzengruber C, Pachinger O, Auer J, Franke H, et al. Valvuloplasty with glutaraldehyde-treated autologous pericardium in patients with complex mitral valve pathology. Ann Thorac Surg. 2001;71:78-85.

3. Gregory F Jr, Takeda R, Silva S, Façanha L, Meier MA. A new technique for repair of mitral insufficiency caused by ruptured chordae of the anterior leaflet. J Thorac Cardiovasc Surg. 1988;96:765-8.

4. Perier P, Hohenberger W, Lakew F, Batz G, Urbanski P, Zacher M, et al. Toward a new paradigm for the reconstruction of posterior leaflet prolapse: midterm results of the "respect rather than resect" approach. Ann Thorac Surg. 2008;86: 718-25.

5. Cochran RP, Kunzelman KS. Comparison of viscoelastic properties of suture versus porcine mitral valve chordae tendineae. J Card Surg. 1991;6:508-13. 